\title{
EL DERECHO AL VOTO DE LOS EXTRANJEROS EN LAS ELECCIONES MUNICIPALES ESPAÑOLAS. ¿INTEGRACIÓN O INTERÉS?*
}

\author{
Alfonso ORTEGA GIMÉNEZ** \\ Lerdys Saray HEREDIA SÁNCHEZ***
}

RESUMEN: La idea de integrar a los inmigrantes en el círculo de participación ciudadana es el núcleo del sistema de integración. Sin embargo, la participación en la vida pública de un país, no es el único elemento que puede situar a un inmigrante en condiciones de integración. El panorama español vigente recoge entre el catálogo de derechos y libertades de los que gozan los extranjeros en España el derecho de participación pública; un derecho cuyo ejercicio queda limitado a aquellos que residen legalmente en nuestro país. Conviene hacer un esfuerzo político más abarcador de otros aspectos de la realidad de la inmigración - como la protección de los derechos fundamentales, el acceso al mercado laboral, la asistencia sanitaria en condiciones de igualdad, etcétera- donde el derecho al voto se estructure sobre bases sólidas de actuación y no como un elemento más de una campaña electoral dirigida a la captación de votos.

ABSTRACT: The idea of integrating the immigrants in the circle of civil participation is the nucleus of the system of integration. Nevertheless, the participation in the public life of a country is not the only element that can place an immigrant in conditions of integration. The Spanish panorama counts the right of public participation among the catalogue of rights and freedoms which foreigners enjoy in Spain, but the exercise of this right is still limited to those who legally reside in our country. It is necessary to implement a wider political effort which includes other aspects of the reality of immigration - such as the protection of fundamental rights, access to the labour market, health assistance in conditions of equality, etc. - where the right to vote is constructed on solid bases of performance and not as just another element in an electoral campaign aimed at vote getting.

RÉSUMÉ: L'idée d'intègre aux migrants dans le circule de participation citadine est le noyau du system d'intégration. Malgré, la participation dans la vie public d'un pays, n'est pas le seule élément qui peux situer un immigrant en conditions d'intégration. Le panorama espagnol actuel prendre entre le catalogue des droit et libertés de ceux qui joui les étrangers en Espagne, le droit de participation public un droit dont exercice reste limité a ceux qui réside légalement dans notre pays. Il faut que on fasse un effort politique plus accaparant des autres aspects de la réalité de l'immigration - comme la protection des droits fondamentaux, l'accès au marché du travail, l'assistance sanitaire en conditions d'égalité, etc.- par lequel le droit a voter soit structure sur bases solides d'actuation et pas comme un élément de plus d'un campagne électoral dirigé a capter des votes.

* Comunicación presentada al V Congreso sobre la Inmigración en España: Migraciones y Desarrollo Humano (Valencia, 21-24 de marzo de 2007).

** Profesor colaborador de Derecho internacional privado en la Universidad "Miguel Hernández" de Elche.

*** Profesora asociada de Derecho internacional privado en la Universidad de Alicante. Responsable CeiM-Alicante. 
SUMARIO: I. Planteamiento. II. Inmigrantes y espacio europeo. Estado actual de la cuestión. III. Análisis de la Proposición no de Ley sobre la Extensión del Derecho a Voto en las Elecciones Municipales a los Extranjeros Residentes Legales.

IV. Consideraciones finales.

\section{PLANTEAMIENTO}

1. La idea de integrar a los inmigrantes en el círculo de participación ciudadana es el núcleo del sistema de integración, al menos, eso es lo que reflejan los estudios sobre este tema. ${ }^{1}$ Sin embargo, la participación en la vida pública de un país, no es el único elemento que puede situar a un inmigrante en el utópico estatus de integración. Conviene hacer un esfuerzo político más abarcador de otros aspectos de la realidad de la inmigración - como la protección de los derechos fundamentales, el acceso al mercado laboral, la asistencia sanitaria en condiciones de igualdad, etcétera- donde el derecho al voto se estructure sobre bases sólidas de actuación y no como un elemento más de una campaña electoral dirigida a la captación de votos.

2. El panorama español vigente recoge entre el catálogo de derechos y libertades de los que gozan los extranjeros en España el derecho de participación pública; un derecho cuyo ejercicio queda limitado a aquellos que residen legalmente en nuestro país. Por otro lado, el artículo 6o. de la Ley de Extranjería, ${ }^{2}$ bajo el epígrafe Participación pública, establece, en su apartado primero, que "los extranjeros residentes en España podrán ser titulares del derecho de sufragio en las elecciones municipales atendiendo a criterios de reciprocidad, en los términos que por Ley o Tratado sean establecidos para los españoles residentes en los países de origen de aquéllos".

3. En este contexto, el debate está servido ya que en agosto de 2006 los grupos parlamentarios Partido Socialista Obrero Español (en adelante, PSOE) e Izquierda Unida-Iniciativa per Catalunya els Verds (a partir

1 Por ejemplo, Olivám López, F, Constitución y extranjería, Madrid, Dykinson, 2004, pp. 123-156.

2 Nos referimos a la Ley Orgánica 4/2000, de 11 de enero, sobre derechos y libertades de los extranjeros en España y su integración social, en su redacción dada por la Ley Orgánica 8/2000, de 22 de diciembre, por la Ley Orgánica 11/2003, de 29 de septiembre y por la Ley Orgánica 14/2003, de 20 de noviembre. 
de ahora, IU-ICV) presentaron una propuesta en el Congreso de los Diputados para que los inmigrantes (no comunitarios) puedan emitir su voto en las elecciones municipales.

Aprovechando la actualidad del tema, y las posibilidades de estudio que ofrece desde la perspectiva jurídica, el presente análisis se estructura en las siguientes partes: primero, un acercamiento a las generalidades sobre el estado actual de la relación entre inmigrantes, minorías y espacio europeo; para posteriormente analizar desde una perspectiva crítica, el derecho al voto como medio de integración social de los extranjeros y su reflejo en la Proposición no de Ley sobre la Extensión del Derecho a Voto en las Elecciones Municipales a los Extranjeros Residentes Legales. Finalmente, se aportan una serie de consideraciones a modo de conclusiones y algunas referencias a la bibliografía relacionada con el tema, así como a las páginas de Internet donde podemos encontrar información al respecto.

\section{INMIGRANTES Y ESPACIO EUROPEO. ESTADO ACTUAL DE LA CUESTIÓN}

4. Desde 1989 la inmigración en Europa representa el elemento básico del cambio demográfico en esta zona, y aunque no sea la solución definitiva a los problemas de envejecimiento y del mercado laboral europeo, supone un dato muy positivo para el crecimiento económico y para el sostenimiento de los sistemas de protección social.

5. La inmigración y el asilo no se encontraban entre las competencias originales de las instituciones europeas. Las bases para el tratamiento de estos temas se establecieron entre 1986 y 1992. De este modo, el objetivo de crear un mercado interior favoreció la consideración de la inmigración como una cuestión que debía ser abordada a nivel europeo: la firma del Acta Única Europea en 1986, que incluía un programa de armonización de la política de inmigración, favoreció el desarrollo de una cooperación más estrecha entre los Estados miembros.

Las políticas de inmigración y asilo se incorporaron a la agenda del proceso de integración con el Tratado de Maastricht, como materias integrantes de la Cooperación en Justicia y Asuntos de Interior, pilar en el que se adoptan las decisiones siguiendo mecanismos de cooperación intergubernamental. El proceso de comunitarización de las políticas de inmi- 
gración y asilo continúa abierto. El Consejo Europeo de Tampere, celebrado en octubre de 1999 y dedicado en exclusiva a la creación del espacio de libertad, seguridad y justicia, se cerró con la adopción de varias conclusiones en materia de asilo e inmigración, y con el encargo a la Comisión de que elaborara un plan de trabajo en el que se incluiría un sistema común de asilo e inmigración. La postura general de la UE hacia la inmigración es claramente restrictiva. La tragedia de Dover (junio de 2000) puso de relieve los efectos no deseados y perversos de las leyes restrictivas: los flujos migratorios clandestinos no desaparecen, lo que ha obligado a poner en marcha periódicamente procesos de regularización, ${ }^{3}$ con sus consecuencias en todos los planos de la vida social de los países miembros del espacio comunitario.

6. A continuación se analizan los principales elementos relacionados con la ciudadanía europea y su conexión con el ejercicio del derecho al voto como factor de integración social.

\section{La ciudadanía de la Unión Europea}

7. El concepto de "ciudadanía" es una categoría básica del discurso político moderno, recordemos que en ella se recogen los referentes normativos y los argumentos de legitimidad de la organización política de las sociedades democráticas. Es la categoría jurídico-política que mejor expresa la pertenencia a una comunidad política concreta, cuyo ordenamiento jurídico y entramado institucional serían, según este discurso, el resultado de la unión contractual de individuos capaces de negociar las condiciones del contrato que les asocia y que, con base en la libertad con la que es logrado y aceptado el acuerdo, tiene carácter vinculante. La libertad y la igualdad de todos los miembros de la comunidad política son las notas esenciales de la ciudadanía y, al mismo tiempo, las condiciones de legitimidad de las formas de organización e institucionalización de dicha comunidad. ${ }^{4}$

3 Véase sobre este tema, Delgado Godoy, L., "La inmigración en Europa: realidades y política", en Unidad de Políticas Comparadas, CSIC, Documento de Trabajo 02-18, disponible en http://www.iesam.csic.es/doctrab2/dt-0218.pdf, consultado el 25 de octubre de 2006.

4 Sobre esta cuestión véase Ramiro Avilés, M., "El derecho al voto de los inmigrantes, una utopía para el siglo XXI", en http://www.uv.es/CEFD/12/ramiro.pdf, consultado el 23 de octubre de 2006. 
La libre circulación de personas en Europa ha sido desde el inicio del proceso de integración comunitario un elemento clave de su desarrollo. El doble contenido del ejercicio de la libertad de circulación, económico y político, ha servido para fomentar y cumplir con los objetivos básicos de la Unión. ${ }^{5}$

La evolución de la libertad comunitaria de circulación se ha ido diseñando a lo largo de estos años como un verdadero acicate para la integración de los colectivos de ciudadanos que trasladan su residencia y vida a otros países distintos a los de origen. En este sentido, el derecho comunitario ha venido aportando una serie de normas jurídicas destinadas a perfilar el ejercicio pleno de los derechos de los ciudadanos europeos y sus familiares, allá donde decidan residir; recordemos, por ejemplo, algunas de las medidas comunitarias que obligaron a los Estados miembros a modificar sus normas internas, en especial, la Directiva 38/2004, de 29 de abril de 2004, relativa al derecho de los ciudadanos de la Unión y de sus familiares a circular y residir libremente por el territorio comunitario. ${ }^{6}$

En la base de las prerrogativas de las que disfrutan los ciudadanos comunitarios está la aplicación del principio de libre circulación de personas dentro de la Unión Europea el cual ha sido desde el inicio del proceso de integración una pieza clave que se complementa con la libre circulación de trabajadores. En la práctica, la libertad de movimiento dentro de Europa se ha convertido en un pilar fundamental y es un derecho que se encuentra en permanente evolución y cambio, ${ }^{7}$ de forma tal que para entender cómo se encuadra dentro de la estructura de funcionamiento de las políticas comunitarias, se deben tener presente, en todo momento, dos cuestiones básicas: una, que por un lado la evolución del concepto de "ciudadanía comunitaria" se ha ido adaptando de acuerdo con las circunstancias históricas que han rodeado el proceso de creación de la

5 Sobre este tema, son muy interesantes las reflexiones que realizan Adam Muñoz, D. y Blázquez Rodríguez, I., Nacionalidad, extranjería y ciudadanía de la Unión Europea, Madrid, Colex, 2005, pp. 175 y ss.

6 Doce, L, núm. 158, de 30 de abril de 2004, y corr. de errores en Doce, L, núm. 23, de 9 de junio de 2004.

7 Sobre este tema son muy interesantes las reflexiones aportadas por Adam Muñoz, D. y Blázquez Rodríguez, I., op. cit., nota 5, pp. 175 y ss. 
Unión Europea ${ }^{8}$ y, por otro, que como consecuencia de este proceso, la movilidad de las personas dentro del territorio comunitario ha pasado de tener una vocación casi exclusivamente económica a adquirir una dimensión de carácter político. Por supuesto, que en el terreno que nos ocupa esta evolución trasciende en todas y cada de las consideraciones que a favor de los ciudadanos comunitarios se han argumentado en cada momento de la evolución política del Estado.

\section{Los ciudadanos de los países no europeos y su integración} social: el derecho al voto como medio de integración social

8. En el Consejo Europeo de Tampere, ${ }^{9}$ se prestó especial atención a la situación de aquellos ciudadanos de terceros países que llevan mucho tiempo instalados en la Unión. La primera propuesta en este sentido presentada por la Comisión en diciembre de 1999 se refiere al derecho a la reagrupación familiar de los ciudadanos de los terceros países con permiso de residencia legal, y de los más recientes, el recogido en el estatuto de los residentes de larga duración. ${ }^{10}$

De acuerdo con esta normativa, una vez adquirido el estatuto de residente de larga duración, el interesado tendrá derecho a toda una serie de prestaciones en las mismas condiciones que los nacionales, en particular en materia de:

- Condiciones de acceso a un empleo asalariado y a una actividad por cuenta propia, así como condiciones de empleo y trabajo (descanso semanal, normas de higiene, vacaciones anuales, salario, condiciones de despido).

- Educación y formación profesional, reconocimiento de títulos.

8 Basta pensar que las categorías de ciudadanos que se han venido favoreciendo de esta libre circulación ha sido cambiante, de acuerdo con los requisitos y formalidades exigidos para ello.

9 Para consultar los documentos relacionados con las conclusiones de este Consejo, véase el siguiente vínculo en Internet http://europa.eu.int/council/off/conclu/oct99/oct99 _es.htm, consultado el 25 de octubre de 2006.

10 Directiva 2003/109/CE del Consejo, de 25 de noviembre de 2003, relativa al estatuto de los nacionales de terceros países residentes de larga duración, Doce, L16, de 23 de enero de 2004. 
- Protección social (subsidios familiares, pensiones de jubilación) y asistencia sanitaria.

- Asistencia social (renta mínima, pensiones mínimas, ayuda médica gratuita).

- Ventajas sociales y fiscales, acceso a bienes y servicios.

- Libertad de asociación y afiliación, y participación en organizaciones de trabajadores o patronos.

- Libre acceso al conjunto del territorio del Estado miembro concerniente.

La Ley 4/2000 reconoció en su artículo 6o. que los extranjeros residentes podrían ser titulares del derecho político de sufragio en las elecciones municipales en los términos que establecieran las leyes y los tratados. Con posterioridad, a través de la Ley 8/2000, como ya se ha apuntado, este texto fue modificado de manera radical en los siguientes términos: "los extranjeros residentes en España podrán ser titulares del derecho de sufragio en las elecciones municipales, atendiendo a criterios de reciprocidad, en los términos que por la ley o tratados sean establecidos para los españoles residentes en los países de origen de aquellos".

En España, la política de integración es en su mayor parte responsabilidad de los municipios y comunidades autónomas, y, dado que muchos municipios carecen de medios financieros y de infraestructuras suficientes, se encuentran con numerosas dificultades para hacer frente a ella.

A mediados de los noventa se aprobó el Plan Nacional para la Integración Social de los Inmigrantes y se puso en marcha el Foro para la Integración Social de los Inmigrantes, que debía ofrecer asesoría relativa a las medidas de integración planificadas. A partir de 2000 se ha desvirtuado claramente la política de integración social hasta el punto que las unidades administrativas que se encargan de ella llegaron a depender orgánicamente del Ministerio del Interior. Por suerte, hoy el Ministerio de Trabajo y Asuntos Sociales ha rescatado el control de estos temas y los esfuerzos se sitúan en un plano social de atención por parte del Estado.

En octubre de 1999 el Partido Popular introdujo la cuestión de la inmigración en el debate político y desde entonces ha venido creciendo la confrontación en torno al mismo: la polémica más fuerte está relacionada con los derechos de los inmigrantes indocumentados que se encuentran en España. Pero hoy, de cara a unas elecciones que decidirán el futuro 
político de los próximos años, se introduce ésta, la que tiene que ver con el derecho de sufragio.

Para integrar esa diversidad y facilitar la formación de una verdadera sociedad europea, es necesario un proceso de adaptación y amoldamiento mutuo - tanto de los inmigrantes, como de toda la sociedad de acogida- Este proceso requiere la participación activa de todas las partes involucradas. La sociedad española no puede esperar, de forma absoluta, que los inmigrantes se comprometan en firme a integrarse en la sociedad y a aceptar sus valores fundamentales, de una forma tasada. Este proceso está conformado por un conjunto de factores, de los cuales podríamos concretar tres de los más importantes: 1) El reconocimiento del otro como portador de símbolos iguales a los de la sociedad de acogida; 2) La desvinculación de la participación política en nuestra sociedad del concepto de ciudadanía, y 3) El reconocimiento de la persona como centro del derecho.

\section{ANÁLISIS DE LA PROPOSICIÓN NO DE LEY SOBRE LA EXTENSIÓN DEL DERECHO A Voto EN LAS ElECCIONES MuniCIPALES A LOS EXTRANJEROS RESIDENTES LEGALES}

\section{Marco jurídico del derecho de sufragio de ciudadanos extranjeros en España}

9. El punto de partida en esta materia es nuestra Constitución que señala, en el artículo 23, que los ciudadanos tienen derecho a participar en asuntos públicos, directamente o por medio de representantes, libremente elegidos en elecciones periódicas por sufragio universal. En esta línea, el artículo 13.2 de la propia Constitución Española"1 matiza que "solamente los españoles serán titulares de los derechos reconocidos en el artículo 23, salvo lo que, atendiendo a criterios de reciprocidad, pueda establecerse por tratado o por ley para el derecho al sufragio activo y pasivo en las elecciones municipales". Así, en la actualidad, este derecho se reconoce

11 Este precepto ha sido, hasta la fecha, el único que se ha modificado de nuestra Constitución Española —el 27 de agosto de 1992-, por existir contradicción entre su redacción anterior y el artículo 8.B del Tratado Constitutivo de la Comunidad Europea, asumido por el Tratado de la Unión Europea, que otorga a todos los ciudadanos comunitarios el derecho de sufragio activo y pasivo en las elecciones municipales, con independencia del país de su residencia. 
ya a los residentes en España con nacionalidad de otros países de la Unión Europea. Por el contrario, los nacionales extracomunitarios, en España, pueden votar en las elecciones municipales si un español puede ejercer su derecho al voto en el país de origen de éstos; es decir, gozarán del derecho de sufragio todos aquellos nacionales originarios de países con los que España tenga suscrito tratado internacional, en virtud del principio de reciprocidad.

De esta forma, España tiene suscritos Tratados y Acuerdos Generales de Cooperación y Amistad con países como Argentina, Venezuela, Chile, Uruguay y Colombia, en los que se reconoce el derecho de sufragio en las elecciones municipales de los residentes legales, si bien se remite la efectividad del derecho a lo que establezcan los Convenios específicos o legislación de desarrollo, aspectos que no se han concretado hasta la fecha.

Por otro lado, existen Estados extracomunitarios, tales como Islandia y Nueva Zelanda, en los que, a pesar de no existir acuerdo de reciprocidad, los ciudadanos españoles que residen allí, gozan del derecho al sufragio, en algunos Estados, activo; y, en otros, activo y pasivo.

10. Además, en virtud de la Resolución del Parlamento Europeo sobre la situación de los derechos fundamentales en la Unión Europea (2000/2231(INI)), en sus artículos 121 y 122, la propia Unión Europea recomienda a los Estados miembros que amplíen el derecho de voto a los ciudadanos de terceros países con años de residencia en la Unión Europea, y que extiendan el derecho de sufragio activo y pasivo en las elecciones municipales europeas - que el artículo 19 del Tratado Constitutivo de la Comunidad Europea concede a los ciudadanos de la Unión-, a todos los ciudadanos de terceros países que residen legalmente en el territorio de la Unión Europea, desde hace como mínimo tres años.

En dicha Resolución se recomienda a los Estados miembros que ratifiquen, los que aún no lo hayan hecho - como es el caso de España— la Convención Europea sobre la Participación de los Extranjeros en la Vida Pública Local, de 5 de febrero de 1992, que recoge el compromiso de los Estados a conceder el derecho al sufragio activo y pasivo en las elecciones locales a los residentes extranjeros, siempre que cumplan las mismas condiciones que se exigen a los nacionales. 


\section{Perspectiva crítica de futuro. Proposición no de Ley} sobre la Extensión del Derecho a Voto en las Elecciones Municipales a los Extranjeros Residentes Legales

11. El pasado 16 de agosto de 2006, los Grupos Parlamentarios Socialista e Izquierda Unida-Iniciativa per Catalunya els Verds, presentaron una Proposición no de Ley sobre la Extensión del Derecho a Voto en las Elecciones Municipales a los Extranjeros Residentes Legales, para su debate en el Pleno de la Cámara.

Así, se instaba al Gobierno a:

1) Proceder a la negociación y firma de acuerdos o convenio con los países con mayor número de nacionales residentes legales en España y, especialmente, con aquellos con los que ésta tiene relaciones históricas, políticas y culturales más estrechas, al objeto de que dichos nacionales puedan votar y ser elegidos en las elecciones municipales en España con arreglo al artículo 13.2 de la Constitución [en particular, con Argentina, Venezuela, Uruguay, Chile y Colombia, países con los que España ya ha firmado un tratado de amistad que incluye el voto en las elecciones municipales de los residentes en ambos países, pero que no han sido ratificados]; 2) Solicitar del Consejo de Estado un informe sobre la aplicación del artículo 13.2 de la Constitución a los efectos de la participación de los extranjeros residentes en España en las elecciones municipales, y, particularmente, sobre la interpretación de los términos "criterios de reciprocidad" a que se refiere el precepto citado; [y], 3) La firma y ratificación del Convenio europeo sobre participación de los extranjeros en la vida pública local, de 5 de febrero de 1992.

12. Para hacer posible el derecho al voto de los nacionales no comunitarios en las elecciones municipales, España debería ratificar los convenios ya suscritos con países como Argentina, Venezuela, Chile, Uruguay y Colombia, y firmar otros para reconocer el derecho de sufragio en las municipales con Estados como Marruecos o Ecuador. ${ }^{12}$

12 Téngase en cuenta, por ejemplo, que Marruecos es el país del que procede el mayor número de inmigrantes con autorización de residencia en régimen general (17.98\%), seguido de Ecuador (12.12\%); en tercera posición aparece Colombia (7.53\%) y después Rumania (6.78\%), mientras que de China procede un $3.31 \%$, de Perú un $3.09 \%$ y de Argentina un $2.93 \%$. 
13. En este contexto, parece que —al grito de "iQueremos votar!" o "Cotizo, luego voto"- la Proposición del Gobierno tomó cuerpo, y el voto de los extranjeros residentes legales en España pronto se convertiría en uno de los ejes de próximas elecciones municipales. Según los datos de la Secretaría de Estado de Inmigración, hasta el 30 de junio de 2006, los ciudadanos comunitarios - de los 25 Estados miembros de la Unión Europea- alcanzan los 619,341. A los tradicionales votantes de los 15 miembros de la Unión Europea, que acuden con regularidad a las urnas desde 1999, se sumarán los miembros de los 10 nuevos Estados comunitarios. En España hay, hasta mediados de 2006, aproximadamente 63,000 de ellos con autorización de residencia. La comunidad más importante es la polaca, con 40,000 miembros que viven legalmente en España. Los segundos en importancia son los lituanos, casi 13,000 ciudadanos. Hay otros dos países, Rumania y Bulgaria - cuya entrada en la Unión Europea fue el 1o. de enero de 2007-, que seguramente ayudaron a provocar un revolcón electoral en los municipios donde residen; ya que, en España hay aproximadamente casi 190,000 rumanos y 55,000 búlgaros con autorización de residencia - aunque la cifra real es superior, puesto que según el Instituto Nacional de Estadística (INE) hay 380,000 rumanos empadronados en los municipios españoles y 93,000 búlgaros-.

14. La vinculación entre derechos fundamentales y derechos políticos no se vuelca sobre el funcionamiento del sistema electoral, como sabemos, la participación política es mucho más que la pertenencia a un cuerpo electoral.

\section{CONSIDERACIONES FINALES}

15. Tras lo expuesto, podemos concluir que la inmigración está poniendo a prueba la cohesión social en la sociedad española. Sin embargo, el fenómeno migratorio incide en todo el espacio europeo, con diferencias acusadas en cada uno de los Estados, cada país se encuentra ante escenarios migratorios diferentes y adopta estrategias políticas para afrontarlos de modos distintos, lo que hace que encontrar un compromiso sea una tarea más difícil de lo que pensamos.

16. La Proposición no de Ley sobre la Extensión del Derecho a Voto en las Elecciones Municipales a los Extranjeros Residentes Legales permitiría votar en próximas elecciones municipales a más de 2,000,000 de extranjeros no comunitarios con autorización de residencia en vigor, se- 
gún datos oficiales, una cifra muy alta en comparación con la de extranjeros procedentes de la Unión Europea con derecho a participar en las municipales, que son más de $860,000 .{ }^{13}$

17. No obstante, para que esta propuesta vea la luz, se hará necesario: por un lado, el Informe del Consejo de Estado sobre la aplicación del artículo 13.2 de la Constitución Española, ya que existen países como Ecuador que no permite que allí puedan votar extranjeros, y por lo tanto el criterio de reciprocidad caería en saco roto; y, por otro lado, la ratificación del Ministerio de Asuntos Exteriores español de los Acuerdos ya firmados, y la firma de nuevos Acuerdos con países como Ecuador, Marruecos o Cuba.

18. En cierto modo, si la medida saliera adelante, supondría un paso más en aras a la integración social de los inmigrantes en España. Ahora bien, si ese derecho se supedita a la firma de convenios de reciprocidad, la medida puede quedar en papel mojado, ya que ratificarlos puede llevar años, resultando más que improbable, en estos momentos, que los extranjeros procedentes de los países que no forman parte de la Unión Europea puedan participar en los comicios municipales.

19. Ahora bien, sin duda, el verdadero motivo que impulsó a esta Proposición no fue otra que las elecciones municipales de 2007, los cientos de miles de votos de extranjeros que se pudieron pescar para dar el vuelco político en más de un municipio español. Se habla de fomentar la integración pero, seamos honestos, la verdadera integración no es sólo votar en las elecciones municipales, sino en combinar el derecho del inmigrante a ser admitido en un país de acogida conservando sus raíces, con el deber del inmigrante a respetar las reglas de juego — incluidas las del juego político - preestablecidas en dicho país.

13 En la propia Comunidad Valenciana, se especuló, en su momento, que esta proposición afectaría a cerca de 355,000 extranjeros no comunitarios; cerca de 90,000 - 87,315 - en la provincia de Alicante podrían incorporarse al censo electoral de las elecciones municipales de 2007. Alicante se convertiría, de esta forma, en la cuarta provincia en ciudadanos extracomunitarios legales, sólo superada por Madrid —con 569,797-, Barcelona — con 308,170 - y Murcia — 117,668-. 